\title{
БИОФИЗИКА ПАТОГЕНЕЗА COVID-19 И ВОССТАНОВИТЕЛЬНАЯ ФИЗИОТЕРАПИЯ КОГЕРЕНТНЫМИ МУЛЬТИ-ИЗЛУЧЕНИЯМИ
}

25 мая 2020

\author{
Аржан Суразаков $\mathrm{PhD}^{1}$, Анна Классен ${ }^{2}$ \\ ${ }^{1}$ Директор по науке и разработкам \\ Radiant Life Technologies Ltd \\ arzhan@radiant-life-technologies.com
}

${ }^{2}$ Врач реабилитолог, физиотерапевт, терапевт, dr.annacomra@gmail.com

\section{ГЛАВНЫЕ ТЕЗИСЫ}

- Формирование адекватного иммунного ответа невозможно без достаточного энергообеспечения иммунной функции.

- Тяжелые, критические стадии COVID-19 наступают вследствие функционального истощения и гибели вирусспецифических лимфоцитов на фоне системного энергодефицита организма.

- Биофизическое воздействие соМra-терапии позволяет повысить энергообеспечение клетки для формирования необходимого адаптивного иммунитета.

ЭТАПЫ ИММУНОПАТОЛОГИИ ПРИ COVID-19

1. Дефицит адаптивной иммунной функции

2. Истощение, гибель лимфоцитов

3. Цитокиновый шторм

4. Гибель тканей органов

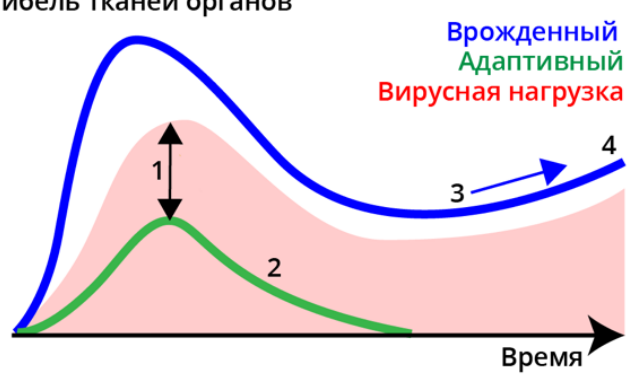

ВОССТАНОВЛЕНИЕ ФУНКЦИОНАЛЬНОГО РЕЗЕРВА С ПОМОЩЬЮ СОМRА-ТЕРАПИИ

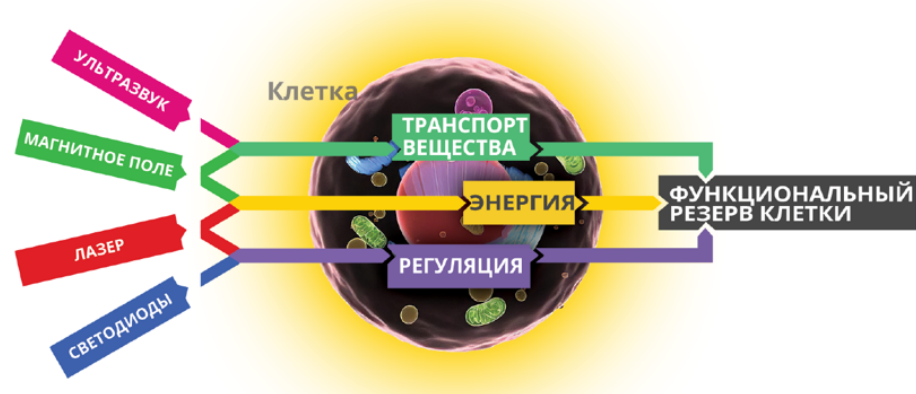

Адекватный и достаточный иммунный ответ на инфекцию SARS-CoV-2

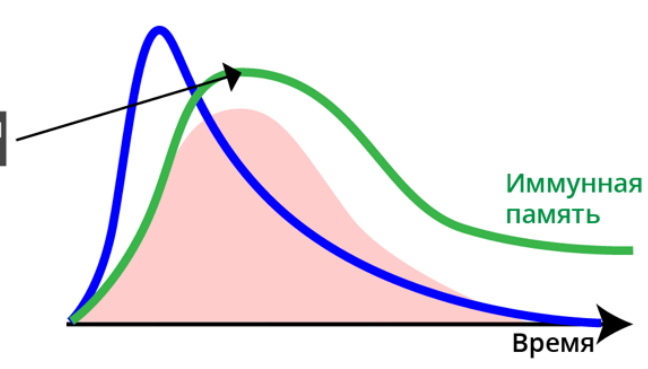




\section{PEЗЮME}

Опубликованные ретроспективные клинические данные указывают на то, что у всех больных с тяжелым, критическим течением коронавирусного заболевания COVID-19 предварительно наблюдался глубокий срыв адаптивного иммунного ответа. Функциональное истощение и последующая гибель Т-лимфоцитов происходят, когда энергозатраты на активацию адаптивного иммунитета значительно превышают доступный функциональный резерв организма. Биоэнергетическая природа патогенеза COVID-19 открывает возможность поддержать организм в борьбе с инфекцией посредством биофизического воздействия. За последние 40-50 лет установлена эффективность лазерного, магнито-лазерного, ультразвукового, монохроматического светового и других низкоинтенсивных методов физиотерапии при острых респираторных вирусных инфекциях, пневмоний различной этиологии, иммунодефицитах. В данной статье в целях проведения восстановительной терапии COVID-19 мы предлагаем использование метода физиотерапии низкоинтенсивными когерентными мульти-излучениями (coherent multiple radiances, сокращенно coMra). Данный метод направлен на комплексное восстановление функционального резерва клетки, организма с помощью низкоинтенсивного биофизического воздействия на внутриклеточный синтез АТФ, микротранспорт вещества и состояние автономной нервной системы. Аппараты соМra-терапии формируют одновременно действующий единый согласованный физиотерапевтический поток, состоящий из лазерного излучения, постоянного магнитного поля, модулированного монохроматического света трех цветов и ультразвукового излучения. Наш десятилетний клинический опыт соМrа-терапии свидетельствует о снижении длительности острых респираторных вирусных инфекций по меньшей мере на 40-50\%.

\section{1. ВВЕДЕНИЕ}

В изучении патологии COVID-19 и поиске эффективной терапии на сегодня остается не освещенной взаимосвязь между биофизическим аспектом этого заболевания и методами низкоинтенсивной комплексной физиотерапии.

Способность иммунной системы человека в определенных пределах противостоять инфекции SARS-CoV-2 не вызывает сомнений. Клинические данные показывают, что адекватный иммунный ответ приводит к успешной элиминации вируса в организме и протеканию COVID-19 в легкой форме или даже асимптоматично у большинства инфицированных [1; 2]. Однако у некоторых из инфицированных, преимущественно пожилого возраста, с коморбидными заболеваниями наблюдается функциональное истощение, а затем и глубокое падение количества лимфоцитов на ранней стадии заболевания [3-5]. В результате не формируется своевременный эффективный иммунный ответ, который способен элиминировать инфекцию. Наступает поздняя стадия заболевания, на которой происходит суперрепликация вируса, массированное поражение органов, в первую очередь, тканей легкого, и возникают состояния, угрожающие жизни [610].

Почему же наступает истощение и срыв функции иммунной системы в момент, когда необходима ее максимально интенсивная работа для спасения жизни? При этом нет данных о прямом разрушении иммунных клеток вирусом SARS-CoV-2.

Необходимо обратить внимание на тот факт, что иммунная защита - это чрезвычайно энергозатратный процесс, потребляющий до $60 \%$ от общего энергетического бюджета организма [11]. Отсюда, происходящее истощение иммунной функции может быть результатом того, что резко возросший расход энергии на активацию иммунитета очень быстро, за несколько дней, исчерпывает резервы организма, уже ослабленного другими хроническими заболеваниями, психологическим стрессом. Наступает состояние острого 
системного энергодефицита, который проявляется в окончательном срыве иммунного ответа и дисфункции других органов и систем.

Таким образом, стратегия лечения COVID-19 должна обязательно включать методы восстановления функции иммунной системы и всего организма, истощенного борьбой с инфекцией [12]. И даже если будет разработана эффективная этиотропная терапия COVID19 (антивирусные препараты), необходимость поддержки физиологических функций организма при тяжелых формах заболевания все равно остается. Например, при гриппе А (H1N1) около 25\% критических пациентов все равно умирали, несмотря на применение специфической антивирусной лекарственной терапии [13].

Биоэнергетическая природа патогенеза COVID-19 открывает возможность поддержать организм в борьбе с инфекцией посредством низкоинтенсивного биофизического воздействия. За последние 40-50 лет установлена эффективность лазерного, магнитолазерного, ультразвукового, монохроматического светового и других методов физиотерапии при острых респираторных вирусных инфекциях, пневмоний различной этиологии, иммунодефицитах.

В данной статье мы предлагаем в целях проведения восстановительной терапии COVID-19 использование метода физиотерапии низкоинтенсивными когерентными мультиизлучениями (coherent multiple radiances, сокращенно coMra), применяемых в приборах, созданных концерном Radiant Life Technologies.

Данный метод направлен на комплексное повышение функционального резерва ткани, органа. Аппараты соМra-терапии посредством использования в них комплексного излучателя формируют одновременно действующий единый согласованный физиотерапевтический поток, состоящий из лазерного излучения, постоянного магнитного поля, модулированного монохроматического света трех цветов и ультразвукового излучения. И поскольку излучения синергично потенцируют друг друга, их интенсивность в аппаратах coMra-терапии в разы и даже на порядки ниже, чем в физиоприборах с отдельными излучениями. Поэтому данный метод является максимально неинвазивным, то есть не нарушающим работу организма как самоорганизующейся системы.

Новизна этого метода заключается не в массированной "накачке" ткани энергией разного вида, а в восстановлении физиологической функции как единого целого посредством повышения эффективности внутриклеточночного синтеза АТФ и нормализации микротранспорта вещества, а также гармонизации состояния автономной нервной системы. Это происходит с помощью низкоэнергетического наведения когерентного состояния локально в освечиваемой ткани и системно через циркулирующие кровь и лимфу, органы нейроэндокринной системы.

Комбинация высокой терапевтической эффективности и безопасности соMra-терапии позволяет ее применение на любой стадии заболевания и реабилитации COVID-19. B условиях эпидемии возможно самостоятельное применение аппаратов соМra-терапии под наблюдением врача в стационаре и на дому при вынужденной самоизоляции.

\section{2. ИММУНОПАТОЛОГИЯ COVID-19}

При достаточном и своевременном иммунном ответе организма на инфекцию SARS-CoV-2 происходит саногенез COVID-19. Заболевание протекает в легкой форме или даже асимптоматично у большинства инфицированных [1; 2]. Следуя за антигенпрезентацией, вирусспецифические В- и Т-лимфоциты обеспечивают необходимые реакции клеточного и гуморального адаптивного иммунитета [14]. В частности отметим, что на 7-9 сутки заболевания происходит быстрый прирост популяции антигенспецифических 
цитотоксических Т-лимфоцитов, которые вызывают лизис клеток инфицированных SARSCoV-2 при минимальном количестве провоспалительных цитокинов [15].

Однако у некоторых инфицированных людей, преимущественно пожилого возраста, с коморбидными заболеваниями происходит срыв иммунного ответа, который предшествует более тяжелым стадиям заболевания [6-10]. Попытаемся восстановить хронологию такой траектории заболевания на основе опубликованных данных:

- Вскоре после инфицирования, наблюдается прогрессия признаков функционального истощения Т-лимфоцитов (экспрессия рецепторов PD-1, TIM-3, CTLA-4, и TIGIT): минимальный уровень в продромальном периоде, увеличение при наличии специфических симптомов и максимум во время нахождения в палате интенсивной терапии $(\mathrm{p}<0,05)[3-5]$.

- Если на 10-12 день после появления симптомов количество лимфоцитов сохраняется выше 20\%, то заболевание протекает в легкой или среднетяжелой форме [16]. Если же происходит падение количества лимфоцитов ниже 5-15\% и далее в течение недели не увеличивается выше 5\%, то наступает критическая стадия, о чем свидетельствует детальный ретроспективный анализ клинических данных, который показал, что лимфоцитопения является, вероятно, лучшим прогностическим индикатором тяжести протекания COVID-19 (Рис. 1, 16).

- У всех больных в критическом состоянии с острым респираторным дистресссиндромом, гипервоспалением предварительно наблюдалось глубокое падение общего количества лимфоцитов, включая CD-4, CD-19, NK клетки [17].

- Существует обратная связь между количеством лимфоцитов и цитокинами [3]: TNFa, IL-6, и IL-10 значительно увеличиваются при уменьшении количества лимфоцитов и значительно уменьшаются во время восстановления лимфоцитов в реконвалесцентном периоде.

- Прогностическая модель, которая была построена методами искусственного интеллекта на основе банка данных о 485 инфицированных SARS-CoV-2 пациентов в госпитале Tongji г. Ухань в Китае показала, что используя лишь показатели лактатдегидрогеназы и количества лимфоцитов, возможно предсказать вероятность летального исхода с точностью выше $90 \%$ [18]. Причем прогностический горизонт составил 18 дней.

На основе анализа иммунопатологической картины заболевания исследователями была высказана гипотеза, что функциональное истощение и глубокое падение количества лимфоцитов лежит в основе тяжелых форм COVID-19, и потому необходимы терапевтические меры по предотвращению такого состояния иммунной системы на ранних стадиях заболевания [3; 7; 19; 20]. 


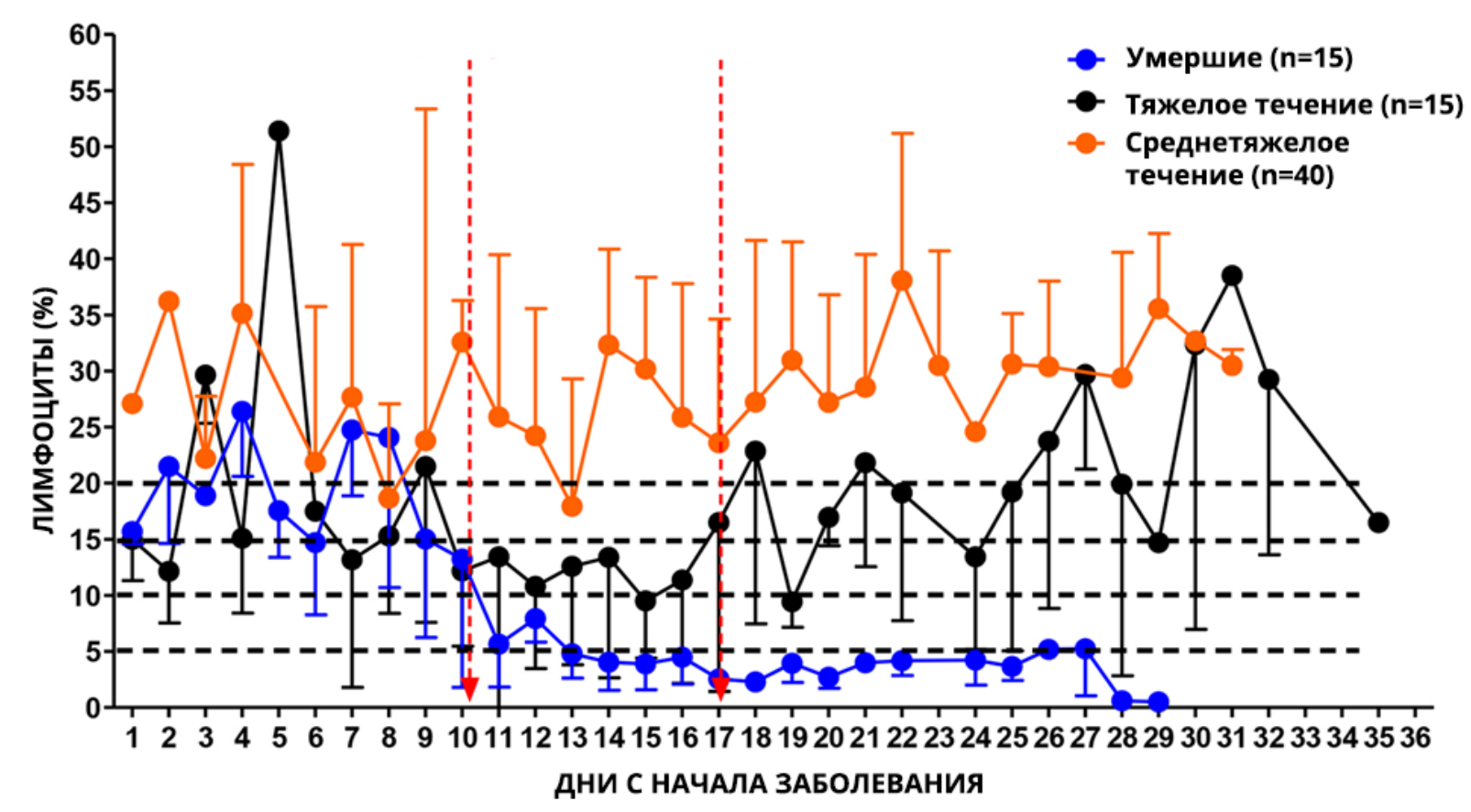

Рисунок 1. Ежедневная динамика количества лимфоцитов у умерших (синий цвет) и выживших пациентов при тяжелом (черный цвет) и среднетяжелом (оранжевый цвет) течении заболевания [модифицированный рисунок из 16].

\section{3. ЭНЕРГООБЕСПЕЧЕНИЕ ИММУННОЙ ФУНКЦИИ}

Если функциональное истощение иммунной системы лежит в основе патогенеза COVID-19, то что вызывает такое состояние? И почему происходит резкое уменьшение количества Тлимфоцитов, несмотря на то, что на их клеточной мембране отсутствует протеин ACE-2, посредством которого вирус SARS-CoV-2 проникает в клетку [21]?

Мы предлагаем гипотезу, что срыв иммунного ответа и последующее развитие тяжелых форм заболевания происходит, когда энергозатраты на активацию адаптивного иммунитета значительно превышают доступный функциональный резерв организма.

Функциональный резерв клетки, органа, организма - это способность интенсифицировать функцию в ответ на повышенную нагрузку без срыва в патологическую дисфункцию.

Величина этого резерва определяется четырьмя ключевыми аспектами жизнедеятельности [22]:

1. Энергетические резервы определяются способностью к интенсификации аэробного и анаэробного энергетического метаболизма в условиях повышенной функциональной нагрузки, гипоксии, интоксикации и т.д.

2. Физиологические резервы зависят от пластичности (реактивности) нейрогуморальных регуляторных возможностей оптимизации работы органов и систем организма.

3. Транспортные резервы определяются возможностью изменения объема и интенсивности обмена веществ, структурной перестройки ткани.

4. Психические резервы определяются мотивацией, эмоциональной устойчивостью к стрессу, навыками преодолевать сложные жизненные ситуации.

Мы полагаем, что взаимозависимость между всеми этими аспектами функционального резерва и определяет, в итоге, тяжесть протекания COVID-19 у индивидуума. Причем, общим знаменателем между возрастом, наличием хронических заболеваний, 
психологическим стрессом и активированной иммунной функцией является энергетическое обеспечение.

Рассмотрим ключевую роль энергообеспечения в формировании достаточного иммунного ответа при COVID-19. Не подлежит сомнению факт, что иммунная система требует значительного количества энергии как на поддержание популяции иммунных клеток, так и на выполнение ими специализированных функций таких как миграция, фагоцитоз и так далее $[11 ; 23]$. Однако важно отметить, что активация иммунного ответа создает дополнительную энергетическую нагрузку на организм. Например, формирование адаптивного иммунитета включает в себя чрезвычайно энергозатратное клональное увеличение популяции Т- и В-лимфоцитов [24]. В целом, если у здорового человека энергозатраты на поддержку неактивной иммунной системы составляют около $20 \%$ от базального метаболического уровня, то инфицирование может увеличить эти энергозатраты до 25\% при легком воспалении и до 60\% при сепсисе (Рис. 2).

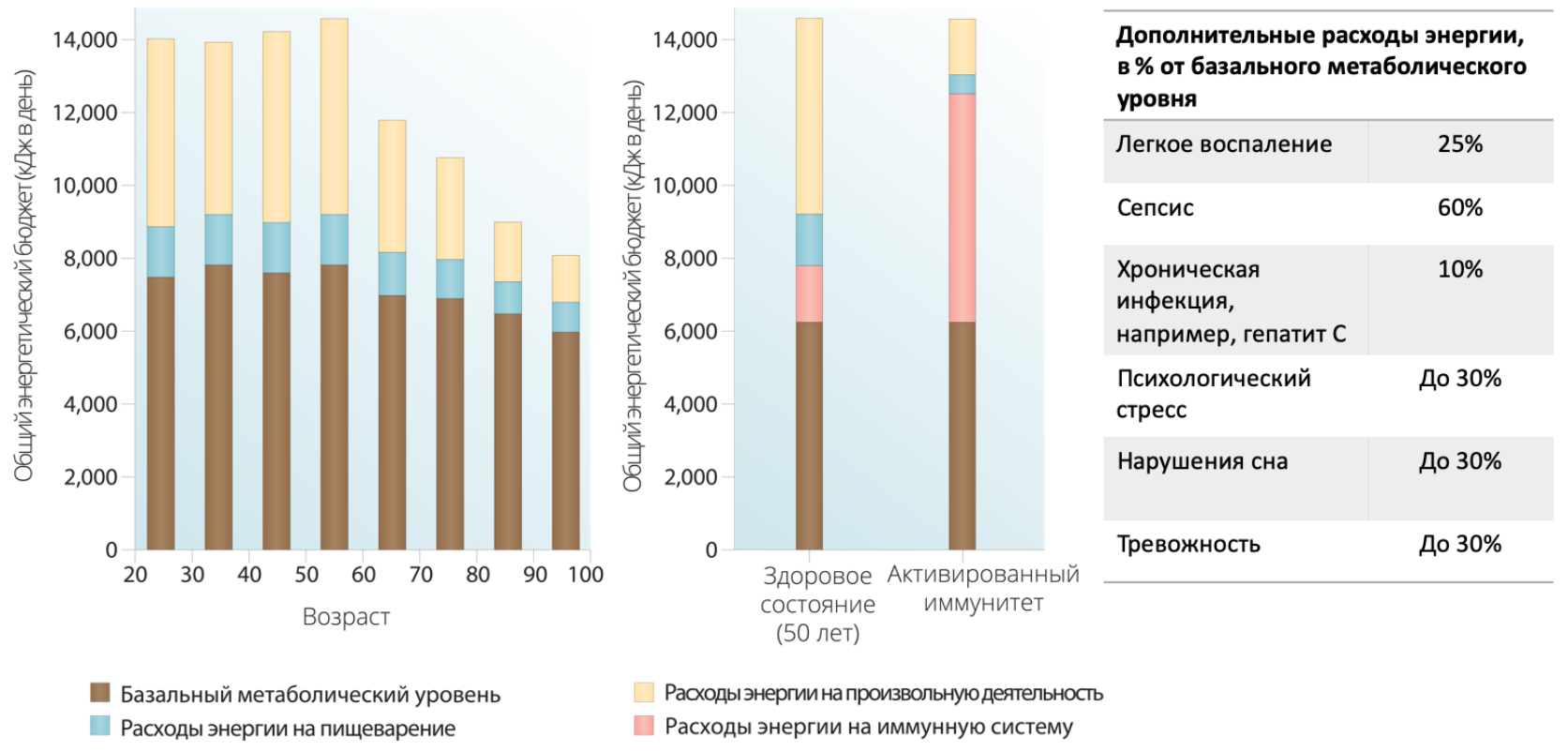

Рисунок 2. Структура общего энергетического бюджета у взрослых и перераспределение энергии на различные виды непроизвольной деятельности [модифицированный рисунок из 11].

Таким образом, у относительно здорового человека дополнительные энергорасходы, вызванные инфекцией SARS-CoV-2, могут достаточно свободно компенсироваться существующим общесистемным резервом. И это происходит без существенного энергетического дефицита в органах и системах организма. Происходит быстрое увеличение популяции антигенспецифичных лимфоцитов на 7-9 день после начала заболевания, которое теперь может пройти в легкой форме или вообще бессимптомно (Рис. 3A). 

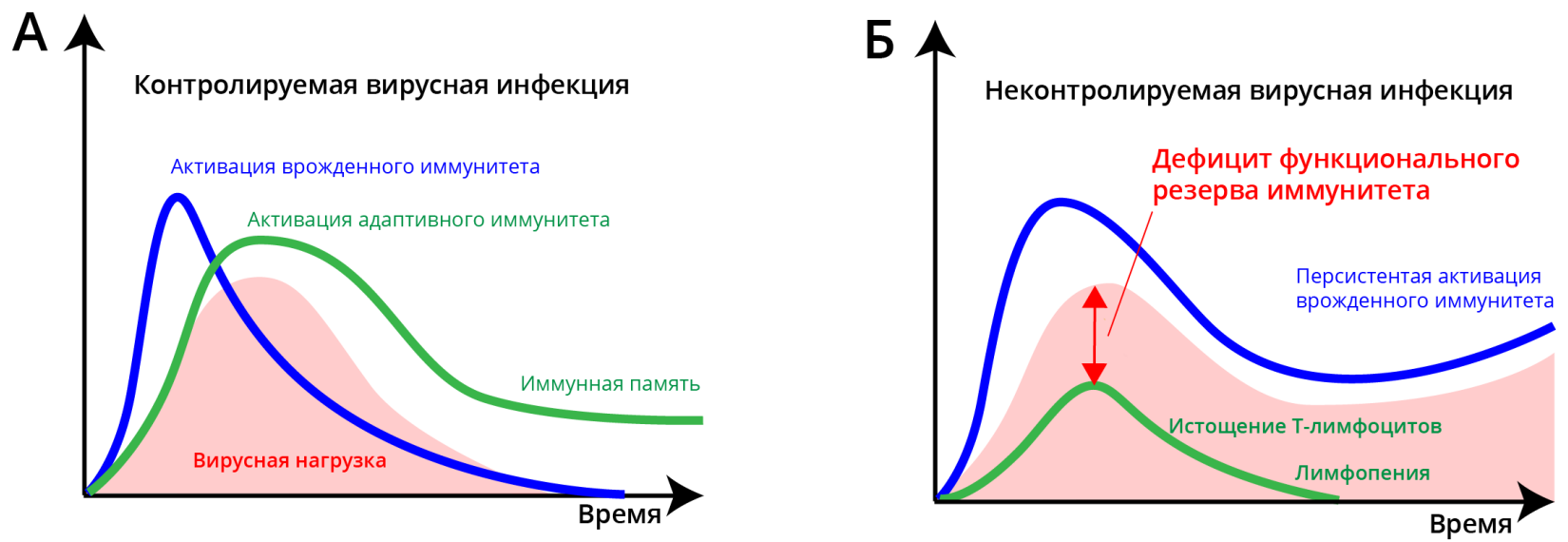

Рисунок 3. При достаточном функциональном резерве организма инфекция успешно контролируется и элиминируется иммунитетом из организма (А). Но если энергозатраты необходимой иммунной активации превышают низкий функциональный резерв организма, то происходит истощение и гибель вирусспецифических лимфоцитов, что ведет к тяжелым формам заболевания, смерти (Б) [модифрицированный рисунок из 20].

С другой стороны, если у человека уже присутствуют другие хронические заболевания (сердечно-сосудистые, респираторные, метаболические и т.д.) до момента инфицирования, то способность организма перераспределить общесистемный энергорезерв на формирование иммунного ответа может быть сильно ограничена (Рис. ЗБ). Напомним, что клеточный энергодефицит является общим признаком практически всех заболеваний [25; 26]. Так, например, хронический гепатит С повышает энергетическую нагрузку на организм примерно на 10\% [27] и Т-лимфоциты уже могут иметь характеристики функционального истощения [28]. Также, поскольку главным энергетическим субстратом активированных лимфоцитов является глюкоза [29], становится понятной повышенная тяжесть протекания COVID-19 среди больных с диабетом [2]. С возрастом также уменьшается функциональный резерв организма, а значит, и сопротивляемость инфекции.

Значительное влияние на энергообеспечение иммунной функции оказывает центральная нервная система в ситуации опасной для жизни (реальной или кажущейся). Психомоторная деятельность, вызванная острым психологическим стрессом, нарушениями сна, болью, тревожностью могут создать дополнительные энергорасходы до $30 \%$ от базального метаболического уровня [11]. Наконец, гнетущее эмоциональное состояние в условиях пандемии, ощущение беспомощности и постоянного страха заражения «невидимым вирусом", изолированность, многократно усиливают психологическую нагрузку на человека, снижают качество его жизни, что не может не сказываться на устойчивости организма к патогенам [30].

В общем итоге, при низком функциональном резерве организма, начиная уже с этапа проявления симптомов заболевания, может наблюдаться прогрессирующее функциональное истощение иммунных клеток, при котором они теряют свои эффекторные и пролиферативные функции. Затем, при наступлении критического энергодефицита, происходит их гибель. Аналогичная картина наблюдается при хронических инфекциях, аутоиммунных и онкологических заболеваниях, но за гораздо более длительное время [28]. При COVID-19 за быстрым и глубоким провалом иммунного ответа следует ничем не сдерживаемое распространение инфекции по всему организму. На более тяжелых и критических стадиях заболевания нарушается гомеостаз организма, происходит гибель ткани легкого, органов сердечно-сосудистой и других систем (Рис. 3Б). 


\section{4. ВОССТАНОВИТЕЛЬНАЯ ФИЗИОТЕРАПИЯ COVID-19 С ПОМОЩЬЮ КОГЕРЕНТНЫХ МУЛЬТИ-ИЗЛУЧЕНИЙ}

Опубликованные рекомендации по использованию физиотерапии при COVID-19 сосредоточены лишь на методах респираторной поддержки: дыхательные упражнения, небулизация, очистка дыхательных путей, кислородная терапия и т.д. [31]. Однако в свете данных о функциональном истощении иммунной системы и общесистемном энергетическом дефиците организма при COVID-19 мы считаем необходимым применение терапии когерентными мульти-излучениями (coMra-терапии) для:

- профилактики заболевания у населения и особенно у медицинских работников, подверженных высокому риску инфицирования SARS-CoV-2;

- восстановительной терапии госпитализированных больных COVID-19 при среднетяжелом, тяжелом, критическом состоянии в комплексе с основными методами;

- самостоятельного лечения легких форм заболевания в условиях самоизоляции на дому для предотвращения развития более тяжелых клинических форм и госпитализации;

- восстановления и реабилитации в реконвалесцентном периоде.

Главной целью применения coMra-терапии при COVID-19 является не прямая манипуляция отдельными звеньями патогенеза, а комплексное восстановление функционального резерва клетки, ткани посредством биофизического воздействия на синтез АТФ, нормализации микротранспорта вещества и состояния автономной нервной системы (Рис. 4). В результате восстановления функции ткани происходит оптимизация работы иммунной системы, систем гомеостаза, ускорение регенерации поврежденных инфекцией органов.

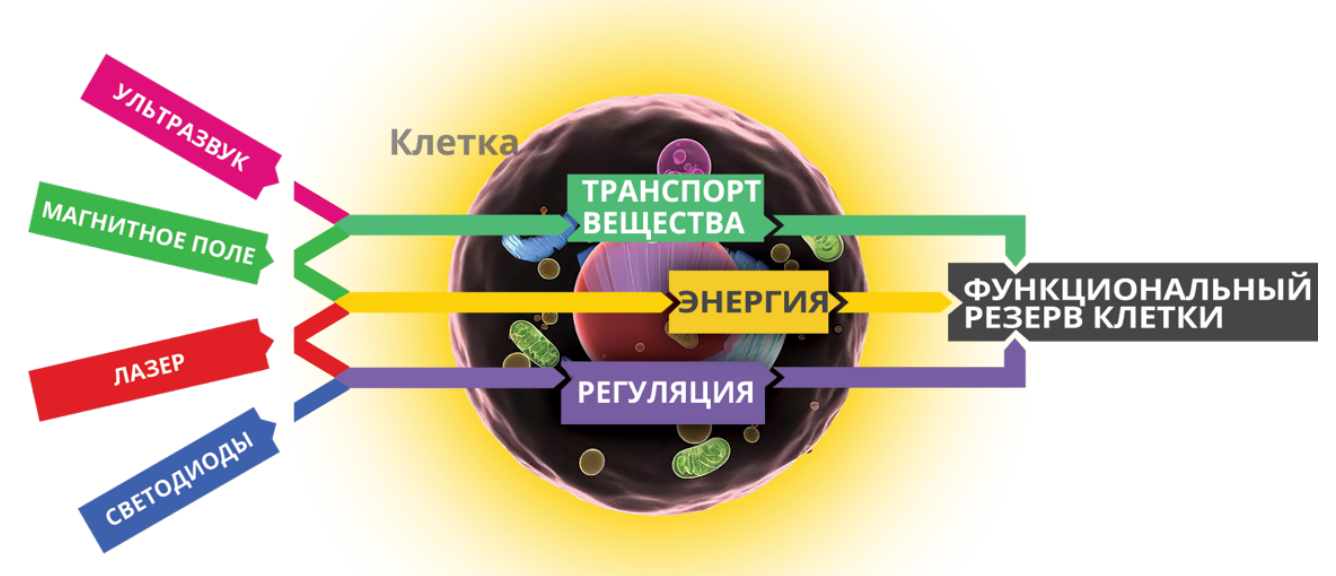

Рисунок 4. Комплексное восстановление функционального резерва клетки, ткани с помощью когерентных мульти-излучений.

Биофизический смысл соМrа-терапии заключается не в массированной "накачке" ткани энергией, а в повышении эффективности процессов метаболизма, посредством увеличения их системной согласованности.

Любая биологическая функция - это результат совместной деятельности ансамбля, состоящего из большого количества индивидуальных элементов (молекул, клеток, органов, систем). Эти ансамбли в живых организмах удерживаются вместе кооперативными и синергетическими взаимоотношениями. Когда же взаимодействует астрономически большое количество элементов, степень их слаженности приобретает первостепенное 
значение. В физике данное явление описывается когерентностью - степенью синхронности между колебаниями различных объектов или процессов.

В течение последних двух десятилетий ряд исследователей заложил теоретические основы существования "когерентного состояния живой ткани" [32]. Значение этой концепции состоит в том, что с точки зрения биофизики - биологическая эффективность зависит от того, как отдельные микроскопические процессы объединяются в сложные макроскопические эффекты. При отсутствии когерентности элементы тратят имеющуюся у них индивидуальную энергию "беспорядочным" образом, практически не оставляя энергии для своей внешней совместной работы. Наступление когерентности устраняет

"беспорядочность" движений, высвобождая энергию для согласованной полезной работы. Таким образом, когерентность, в силу её общей энергетической выгоды, является в рамках одного ансамбля естественным признаком высокой устойчивости, внутренней согласованности и, в целом, здоровья.

Что любопытно, искусственное создание условий повышенной когерентности может быть использовано для повышения эффективности функции в химических и биофизических системах [33]. Здесь и кроется возможность для появления совершенно нового класса медицинских технологий, которые способны в разы повысить эффективность естественных процессов саногенеза, но при этом являются максимально неинвазивными, то есть не нарушающим работу клетки, организма как самоорганизующейся системы.

Действие соМra-терапии основано на создании когерентности одновременно в трех главных аспектах функционального резерва клетки и организма:

1. Лазерное излучение (905 нм или 980 нм, 10 мВт) и постоянное магнитное поле (35 мТл) повышают эффективность энергетического метаболизма посредством фотомагнитного индуцирования электронно-спиновой когерентности в ионрадикальных реакциях синтеза АТФ.

2. Модуляция излучений светодиодов трех цветов (красный, индиго-фиолетовый, желто-зеленый) в определенной последовательности приводит к появлению когерентного (гармонизированного) состояния нервной системы вне зависимости от ее изначального состояния (перевозбуждение, заторможенность).

3. Когерентная механическая вибрация, вызванная абсорбцией ультразвукового излучения (40 кГц) в ткани, повышает эффективность транспорта вещества и ферментативных процессов без механического повреждения структуры и функции клетки.

\section{1 Энергетический аспект функционального резерва}

Лазерное излучение представляет собой высококогерентную форму электромагнитной энергии. С начала 1980-х годов экспериментально (in vitro, in vivo) доказано повышение внутриклеточного содержания АТФ (до 200-300\%) после низкоинтенсивной лазерной терапии (НИЛТ) в условиях ишемии, нарушенной митохондриальной функции, физических упражнений [34-42].

При определенных условиях слабые магнитные поля также способны повысить эффективность ферментативного синтеза АТФ на 200-300\% по сравнению с немагнитным состоянием [43; 44]. Магнитное поле также обладает свойством когерентности, в его присутствии возможно состояние электронно-спиновой когерентности в парах частиц с неспаренным электроном. Это высококогерентное состояние значительно отличается по реакционной способности от реакций синтеза АТФ в немагнитных условиях.

Примечательно, что и низкоинтенсивные лазеры, и магнитные поля оказывают соразмерное влияние на энергетический обмен в клетках: увеличение синтеза АТФ на 200- 
300\%. Неудивительно, что уже в 1990-х годах были созданы приборы магнитноинфракрасно-лазерной терапии (МИЛТ).

Повышение эффективности энергетического метаболизма клетки, в том числе лимфоцитов, последующее восстановление функции ткани, органа и ускорение восстановительных процессов лежит в основе широкой клинической практики НИЛТ, МИЛТ в России в течение последних 40-50 лет [45-47].

Отметим, что, поскольку когерентность физиотерапевтического потока является центральным принципом действия, аппараты соМrа-терапии используют модулированное излучение лазерных диодов непрерывного действия с малой интенсивностью (<10 мВт) и очень низкой спектральной шириной (<0,5 нм). В приборах же НИЛТ, МИЛТ преимущественно используются лазеры более высокой интенсивности или даже пульсированные лазеры с импульсной мощностью до нескольких ватт и бо́льшей спектральной шириной. Такая повышенная энергетическая нагрузка на ткань ограничивает применение при тяжелых, критических состояниях COVID-19, а также у детей и пожилых людей.

Хорошо изучено восстановление функционального резерва иммунных клеток с помощью НИЛТ, МИЛТ при инфекционных заболеваниях, иммуннодефицитах, когда наблюдается замедление, истощение иммунного ответа [обзоры литературы 48; 49-51]. В частности, при лечении органов дыхательной системы отмечались:

- двух- и трехкратное увеличение низкого функционального резерва нейтрофилов у больных при среднем и тяжелом течении внебольничной пневмонии [Рис. 5, 52];

- увеличение количества Т-лимфоцитов и их функциональной активности у больных с тяжелым течением вторичных пневмоний [53];

- нивелирование лейкоцитоза, увеличение содержания Т-лимфоцитов и Thлимфоцитов, повышение IgA и IgG, улучшение функции нейтрофилов у больных муковисцидозом в возрасте от 4 до 11 лет;

- стимуляция пролиферации лимфоцитов, повышение экспрессии мембранных рецепторов Т- и ЕК-клеток, увеличение содержания катионных белков в нейтрофилах у больных раком легкого [54].

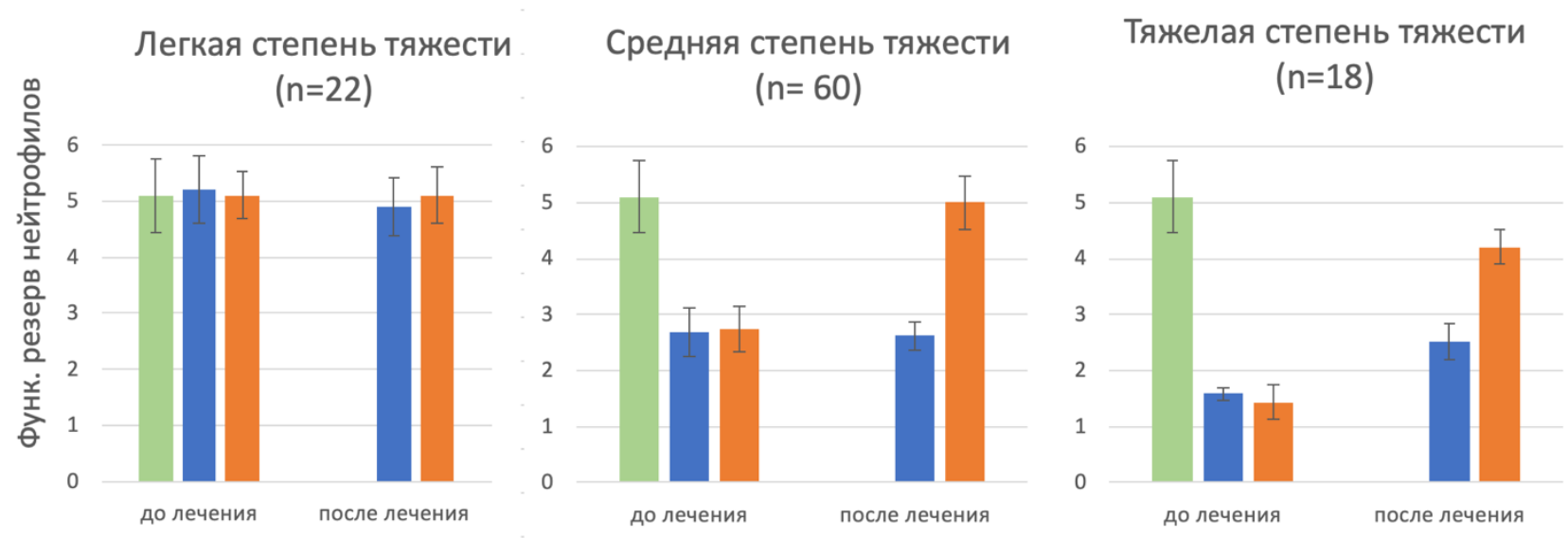

Рисунок 5. Динамика функционального резерва нейтрофилов до и после курса медикаментозной терапии (синий цвет) или медикаментозной терапии с НИЛТ (оранжевый цвет) у больных с внебольничной пневмонией при разной степени тяжести [данные из 52]. Группа сравнения практически здоровых лиц $(n=30)$ показана зеленым цветом. Функциональный резерв нейтрофилов определялся по их способности восстанавливать НСТ в спонтанном и стимулированном НСТ-тесте. 
Наравне с исследованиями, которые демонстрируют повышение низкой иммунной функции после применения НИЛТ или МИЛТ, существуют многочисленные данные об уменьшении гипервоспаления и аутоиммунных процессов, что особенно важно в поздней стадии COVID-19, при так называемом "цитокиновом шторме".

- У детей с тяжелым течением бронхиальной астмы наблюдались положительные сдвиги показателей клеточного звена иммунитета, нормализация уровней $\operatorname{lgG}, \lg A$, $\operatorname{lgM}$ и уровней провоспалительных цитокинов в сыворотке крови, более быстрой положительной динамике клинических показателей и улучшению бронхиальной проходимости [55].

- У больных с плевральным выпотом различной этиологии происходило устранение дисбаланса в соотношении провоспалительных и противовоспалительных цитокинов (ФНО-а, ИЛ-4, ИЛ-1ß) [56].

- У больных инфильтративным туберкулезом легких наблюдались более выраженное снижение цитокинемии, улучшение показателей госпитальной эффективности лечения: ликвидация клинических симптомов, прекращение бактериовыделения, закрытие полостей распада происходит чаще и в более ранние сроки, уменьшение средних сроков предоперационной подготовки больных и длительности стационарного лечения [57].

По нашему мнению, в нормализирующем действии НИЛТ, МИЛТ как на истощенный иммунитет, так и на гипервоспаление нет противоречия. Эти низкоинтенсивные физиотерапевтические методы направлены лишь на повышение функционального резерва клетки, а не на прямое ингибирование или стимуляцию отдельных звеньев иммунитета так, как это делают методы средне- и высокоинтенсивного биофизического воздействия или медикаментозной терапии. Результат первичного биофизического эффекта (повышение эффективности синтеза АТФ) и последующее увеличение потенциальной функции клетки являются нозологически неспецифичными и наблюдаются даже у здоровых лиц. А так как иммунный ответ организма состоит из разных фаз, то более эффективный энергетический метаболизм проявляется как улучшенные провоспалительные процессы в раннем периоде, так и усиленные антивоспалительные процессы в позднем периоде. В целом это выражается в уменьшении длительности и тяжести воспаления, укорочении сроков выздоровления.

\section{2 Регуляторный аспект функционального резерва}

С точки зрения психонейроиммуннологии, регуляторная деятельность нервной системы оказывает значительное влияние на иммунной статус организма [58]. Иннервация лимфоидных органов симпатической и парасимпатической ветвями автономной нервной системы осуществляет прямое воздействие психологического возбуждения или торможения на иммунный ответ организма. Причем как сверхинтенсивное и длительное возбуждение, так и глубокое торможение могут оказать негативное влияние на статус иммунной системы и процессы восстановления, адаптации организма.

В физиотерапии известен метод фотобиомодуляции с помощью монохроматического света (хромотерапия), который используется для лечения расстройств, имеющих значительную вегетативную составляющую. Чрезмерное психологическое возбуждение корректируется синим цветом, заторможенность - красным, а желто-зеленый цвет имеет общее балансирующее действие [59; 60].

В аппаратах соМra-терапии используются светодиоды разной длины волны (цвета), которые создают определенные цветовые последовательности. Так, например, последовательность цветов на Рисунке 6 показывает универсальный гармонизирующий эффект на состояние автономной нервной системы (состояние "когерентности"). Что особенно важно, этот эффект достигается вне зависимости от начального статуса нервной 
системы. Таким образом, аппараты соМrа-терапии можно применять как при гиперактивном состоянии нервной системы человека, так и при ее чрезмерной заторможенности. Данная последовательность является частью патентованного изобретения соMra-терапии.

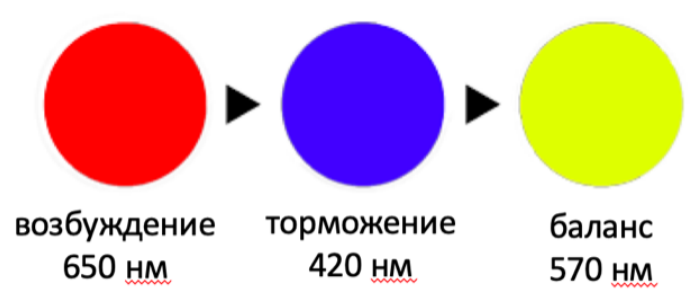

Рисунок 6. Одна из последовательностей цветов, используемых в соМra-терапии.

\section{3 Транспортный аспект функционального резерва}

Кроме достаточного энергообеспечения, функциональный резерв клетки, ткани, также зависит от способности поддерживать эффективный транспорт вещества и высокую ферментативную активность на фоне замедления многих физиологических функций.

Когерентная механическая вибрация, вызванная абсорбцией низкочастотного низкоинтенсивного ультразвукового излучения в ткани, может в разы повысить эффективность микротранспортных, ферментативных процессов [61-63]. Долгосрочная регуляция клеточного метаболизма (часы, дни) зависит от ответа клетки на различные внеклеточные сигналы, как например гормональная или медикаментозная стимуляция [64]. Однако, краткосрочная динамика (секунды, минуты) в основном определяется потоками субстратов и изменениями их местной концентрации вокруг фермента [65]. Недостаток субстрата может оказать особо ингибирующее действие, когда агрегация, слипание замедляет диффузию и блокирует контакт фермента и субстрата [66; 67]. При прохождении акустической волны ультразвука сквозь освечиваемую ткань создаются зоны высокого и низкого давления, ускоряется ток жидкости, что ускоряет доставку субстрата к ферменту, тем самым повышая его эффективность.

Клинический опыт применения ультразвуковой терапии показывает, например, что сочетание ультразвука с тканевым активатором плазминогена (tPA) позволяет повысить лизис тромбов в 2-4 раза, причем это происходит исключительно за счет повышения эффективности ферментативного тромболитического процесса, а не механического разрушения [68; 69].

Также применяется в клинической практике потенцирование НИЛТ с помощью ультразвука [70; 71]. Так, например, при хронической обструктивной болезни легких (ХОБЛ) наблюдается повышение уровня маркеров воспаления, гиперсекреция слизи и нарушение мукоцилиарного клиренса, что приводит к хроническому продуктивному кашлю, прогрессирующей одышке. Поэтому существует необходимость механического воздействия для ускорения обменных процессов, повышения действия лекарственных препаратов, отделения слизи, что и лежит в основе сочетания ультразвука и НИЛТ [47; 72$]$. У больных ХОБЛ последовательное применение НИЛТ и ультразвуковой терапии позволило достигнуть значительно лучших клинических эффектов, чем при использовании только медикаментозной терапии: выделение мокроты, улучшение показателей периферической крови, снижение уровня системных биомаркеров воспаления, улучшение функции внешнего дыхания и общего состояния пациентов [70].

Особо отметим очень низкую силу звукового давления в аппаратах coMra-терапии - 0 дБ (измеряется по логарифмической шкале). Также, в отличие от аппаратов ультразвуковой монотерапии, не используется гель на контакте излучателя и кожи. Таким образом, 
исключается возможность механического повреждения структурных элементов ткани внутренних органов, нарушения высокочувствительных процессов в организме.

Наличие ультразвука в аппаратах соМrа-терапии может оказаться особенно важным в сочетании с антикоагулянтной и антиагрегантной лекарственной терапией COVID-19 [73].

\section{4 Синтез когерентных мульти-излучений в соМra-терапии}

Высокая терапевтическая эффективность соМrа-терапии основана на функциональном единстве энергетических, транспортных и регуляторных аспектов биологической функции. Чтобы достичь такого единства, аппараты соМra-терапии освечивают один и тот же объем ткани одновременно четырьмя или тремя взаимно согласованными физиотерапевтическими излучениями. Это согласование достигается за счёт определенной геометрии всех излучателей в аппарате, соразмерности выходной мощности и модуляции режима работы излучателей на гармонических частотах. Именно в достижении системного когерентного состояния на уровне обмена энергии-веществаинформации и состоит главное воздействие этого метода на живую клетку, ткань, организм.

Безопасность, неинвазивность, отсутствие абсолютных противопоказаний соМra-терапии напрямую следует из синергичности эффектов отдельных излучений. Поскольку действие одного излучения усиливает действие всех других в силу функциональной взаимозависимости их биологических последствий, интенсивность отдельных излучений в аппаратах coMra-терапии в разы и даже порядки ниже, чем в приборах с моноизлучениями, что снижает общую энергетическую нагрузку на ткань. А это делает эту технологию доступным, безопасным методом комплексной физиотерапии.

Для достижения клинически значимого эффекта, многие физиотерапевтические аппараты, которые используют один или два вида источников излучения, работают на достаточно высоких интенсивностях, что может вызвать суммарную энергетическую перегрузки ткани, органа. При комбинировании различных аппаратов физиотерапии необходим расчет допустимых дозировок и точного соблюдения протокола лечения специалистом физиотерапевтом, что особенно важно при более тяжелых формах заболеваний. Эти ограничения могут серьезно препятствовать массовому внедрению этих технологий при эпидемии.

Комбинация высокой терапевтической эффективности и безопасности соМra-терапии имеет решающее значение для повышения четвертого ключевого аспекта функционального резерва организма - психического. Самостоятельное применение coMraтерапии под наблюдением врача в условиях стационара или на дому в условиях вынужденной самоизоляции превращает пассивного реципиента медицинских процедур в активного участника постройки своего здоровья. Это значительно повышает мотивацию к выздоровлению у самого человека и одновременно снимает нагрузку с медицинского персонала, крайне перегруженной системы здравоохранения. А в случае необходимости длительного курса восстановления после перенесенного заболевания, аппараты соMraтерапии могут свободно применяться самостоятельно.

Так как действие соМra-терапии не является патогенспецифическим, данный метод может применяться при любых иммунодефицитных состояниях и появлении новых вирусных эпидемий. Аналогично COVID-19, тяжесть заболевания во время эпидемий SARS-CoV 2003 года, гриппа A/H1N1 в 2009 году, MERS-CoV в 2013 году была ассоциирована с функциональным истощением вирусспецифических лимфоцитов и лимфопенией [20].

За наш десятилетний клинический опыт соМra-терапии мы наблюдали снижение длительности ОРВИ (включая грипп A/H1N1) по меньшей мере на 40-50\% при 
своевременном применении приборов. Тяжесть таких симптомов как головная боль, лихорадка, утомляемость, миалгия также были значительно снижены и лишь в редких случаях требовалось применение лекарственных препаратов. В тех случаях, когда уже применялась интенсивная лекарственная терапия, добавление соМra-терапии способствовало уменьшению количества и дозировки препаратов. Профилактические курсы соМrа-терапии приводили к значительному снижению или полному исчезновению сезонных заболеваний у часто болеющих детей и хронических больных с иммунодефицитами различной этиологии.

В заключение статьи:

- Поскольку соМra-терапия хорошо сочетается с этиотропным, патогенетическим, симптоматическим лечением,

- И у данного метода нет абсолютных противопоказаний

- Мы предлагаем применение метода соМra-терапии на всех стадиях COVID-19, в любом возрасте.

Аппараты соМra-терапии "Дельта" имеют Регистрационное удостоверение Минздрава РФ № ФСЗ 2012/12230 от 29 июня 2012 года.

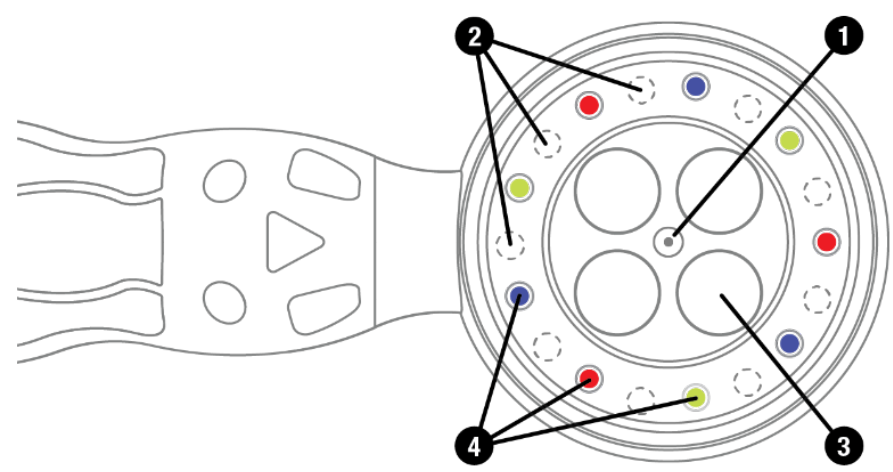

1 Лазер

980 нм, макс. мощность 10 мВт

\section{2 Магнитное поле}

макс. сила 30 мТл

3 Ультразвук

40 кГц, макс. сила звукового давления 0 дБ на контакте

\section{4 Светодиоды}

красный (650 нм), индиго-фиолетовый (420 нм), желто-зеленый (570 нм), макс. сила света 300 мкд

Аппараты coМra-терапии Palm "Ладошка" экономически доступны, удобны для использования на дому.

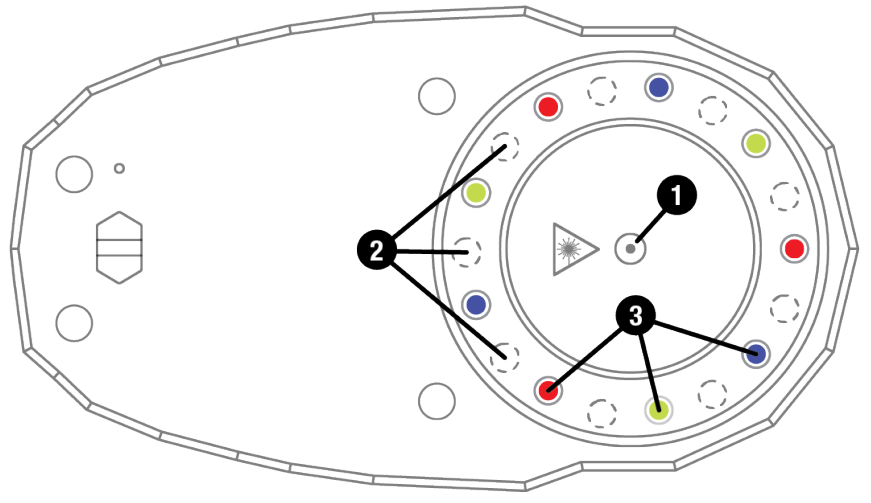

\section{1 Лазер}

980 нм, макс. мощность 10 мВт

\section{2 Магнитное поле}

макс. сила 30 мТл

\section{3 Светодиоды}

красный (650 нм), индиго-фиолетовый (420 нм), желто-зеленый (570 нм), макс. сила света 300 мкд

\section{БЛАГОДАРНОСТИ}

Авторы выражают благодарность Владимиру Разуваеву за конструктивное обсуждение и предложения по улучшению статьи. 


\section{ЛИТЕРАТУРА}

1. Shi Y., $u \partial p$. 2020. COVID-19 infection: the perspectives on immune responses. Cell Death \& Differentiation. doi: 10.1038/s41418-020-0530-3.

2. Guan W.-j., $u$ pp. 2020. Clinical Characteristics of Coronavirus Disease 2019 in China. New England Journal of Medicine. doi: 10.1056/NEJMoa2002032.

3. Diao B., $u \partial p$. 2020. Reduction and functional exhaustion of $\mathbf{T}$ cells in patients with coronavirus disease 2019 (COVID-19). Frontiers in Immunology 11:827. doi: 10.3389/fimmu.2020.00827.

4. Zheng M., $u \partial p$. 2020. Functional exhaustion of antiviral lymphocytes in COVID-19 patients. Cellular \& Molecular Immunology. doi: 10.1038/s41423-020-0402-2.

5. Zheng H.-Y., $u \partial p$. 2020. Elevated exhaustion levels and reduced functional diversity of $T$ cells in peripheral blood may predict severe progression in COVID-19 patients. Cellular \& Molecular Immunology. doi: 10.1038/s41423-020-0401-3.

6. Cao X. 2020. COVID-19: immunopathology and its implications for therapy. Nature Reviews Immunology. doi: 10.1038/s41577-020-0308-3.

7. Qin C., $u \partial p$. 2020. Dysregulation of immune response in patients with COVID-19 in Wuhan, China. Clinical Infectious Diseases. doi: 10.1093/cid/ciaa248.

8. Diao B., $u \partial p$. 2020. Reduction and Functional Exhaustion of T Cells in Patients with Coronavirus Disease 2019 (COVID-19). medRxiv:2020.02.18.20024364. doi: 10.1101/2020.02.18.20024364.

9. Lippi G., Plebani M. 2020. Laboratory abnormalities in patients with COVID-2019 infection. Clinical Chemistry and Laboratory Medicine 1. doi: 10.1515/cclm-2020-0198.

10. Bo X., $u \partial p$. 2020. Suppressed T cell-mediated immunity in patients with COVID-19: a clinical retrospective study in Wuhan, China. Journal of Infection. doi: 10.1016/j.jinf.2020.04.012.

11. Straub R.H. 2017. The brain and immune system prompt energy shortage in chronic inflammation and ageing. Nature Reviews Rheumatology 13:743. doi: 10.1038/nrrheum.2017.172.

12. Ayres J.S. 2020. Surviving COVID-19: A disease tolerance perspective. Science Advances:eabc1518. doi: 10.1126/sciadv.abc1518.

13. Louie J.K., $u \partial p$. 2012. Treatment With Neuraminidase Inhibitors for Critically Ill Patients With Influenza A (H1N1)pdm09. Clinical Infectious Diseases 55 (9):1198-1204. doi: $10.1093 / \mathrm{cid} / \mathrm{cis} 636$.

14. Li X., $u \partial p$. 2020. Molecular immune pathogenesis and diagnosis of COVID-19. Journal of Pharmaceutical Analysis. doi: 10.1016/j.jpha.2020.03.001.

15. Thevarajan I., $u \partial p$. 2020. Breadth of concomitant immune responses prior to patient recovery: a case report of non-severe COVID-19. Nature Medicine 26 (4):453-455. doi: 10.1038/s41591-020-0819-2.

16. Tan L., $u \partial p$. 2020. Lymphopenia predicts disease severity of COVID-19: a descriptive and predictive study. Signal Transduction and Targeted Therapy 5 (1):33. doi: 10.1038/s41392-020-0148-4.

17. Giamarellos-Bourboulis E.J., $u$ zp. 2020. Complex Immune Dysregulation in COVID-19 Patients with Severe Respiratory Failure. Cell Host \& Microbe. doi: 10.1016/j.chom.2020.04.009.

18. Yan L., $u$ p p. 2020. An interpretable mortality prediction model for COVID-19 patients. Nature Machine Intelligence. doi: 10.1038/s42256-020-0180-7.

19. Lin L., $u \partial p$. 2020. Hypothesis for potential pathogenesis of SARS-CoV-2 infection - a review of immune changes in patients with viral pneumonia. Emerging Microbes \& Infections. doi: 10.1080/22221751.2020.1746199.

20. Vardhana S.A., Wolchok J.D. 2020. The many faces of the anti-COVID immune response. Journal of Experimental Medicine 217 (6). doi: 10.1084/jem.20200678. 
21. Zhou P., $u \partial p$. 2020. A pneumonia outbreak associated with a new coronavirus of probable bat origin. Nature 579 (7798):270-273. doi: 10.1038/s41586-020-2012-7.

22. Курзанов А.Н., $и$ дp. 2016. Функциональные резервы организма. Москва: Издательский дом Академии Естествознания.

23. Straub R.H., $u \partial p$. 2010. Energy regulation and neuroendocrine-immune control in chronic inflammatory diseases. Journal of Internal Medicine 267 (6):543-560. doi: 10.1111/j.1365-2796.2010.02218.x.

24. Spies C.M., $u \partial p$. 2012. Energy metabolism and rheumatic diseases: from cell to organism. Arthritis Res Ther 14 (3):216. doi: 10.1186/ar3885.

25. Seppet E., $и$ др. 2009. Mitochondria and energetic depression in cell pathophysiology. International Journal of Molecular Sciences 10 (5):2252-303. doi: 10.3390/ijms10052252.

26. McCance K.L., Huether S.E. 2014. Pathophysiology: The Biologic Basis for Disease in Adults and Children. 7 ed: Elsevier Health Sciences.

27. Piche T., $u \partial p$. 2000. Resting energy expenditure in chronic hepatitis C. Journal of hepatology 33 (4):623-627. doi: 10.1016/S0168-8278(00)80014-8.

28. McLane L.M., $u$ zp. 2019. CD8 T Cell Exhaustion During Chronic Viral Infection and Cancer. Annual Review of Immunology 37 (1):457-495. doi: 10.1146/annurev-immunol041015-055318.

29. MacIver N.J., $u \partial p$. 2008. Glucose metabolism in lymphocytes is a regulated process with significant effects on immune cell function and survival. Journal of leukocyte biology 84 (4):949-957. doi: 10.1189/jlb.0108024.

30. Kiecolt-Glaser J.K., $u$ $\partial p$. 2002. Emotions, Morbidity, and Mortality: New Perspectives from Psychoneuroimmunology. Annual Review of Psychology 53 (1):83-107. doi: 10.1146/annurev.psych.53.100901.135217.

31. Thomas P., $u \partial p$. 2020. Physiotherapy management for COVID-19 in the acute hospital setting: clinical practice recommendations. Journal of Physiotherapy 66 (2):73-82. doi: 10.1016/j.jphys.2020.03.011.

32. Bischof M., Del Giudice E. 2013. Communication and the emergence of collective behavior in living organisms: a quantum approach. Molecular Biology International 2013. doi: $10.1155 / 2013 / 987549$.

33. Scholes G.D., $u \partial p$. 2017. Using coherence to enhance function in chemical and biophysical systems. Nature 543:647. doi: 10.1038/nature21425.

34. Passarella S., $u \partial p$. 1984. Increase of proton electrochemical potential and ATP synthesis in rat liver mitochondria irradiated in vitro by helium-neon laser. $F E B S$ Letters 175 (1):95-99. doi: 10.1016/0014-5793(84)80577-3.

35. Vekshin N.L. 1991. Light-dependent ATP synthesis in mitochondria. Biochemistry international 25 (4):603-11.

36. Karu T., $u \partial p$. 1995. Irradiation with HeNe laser increases ATP level in cells cultivated in vitro. Journal of Photochemistry and Photobiology B: Biology 27 (3):219-223. doi: 10.1016/1011-1344(94)07078-3.

37. Oron U., $u$ дp. 2007. Ga-As $(\mathbf{8 0 8} \mathbf{~} \mathbf{~ m})$ laser irradiation enhances ATP production in human neuronal cells in culture. Photomedicine and Laser Surgery 25 (3):180-182. doi: doi:10.1089/pho.2007.2064.

38. Benedicenti S., $u \partial p$. 2008. Intracellular ATP level increases in lymphocytes irradiated with infrared laser light of wavelength $904 \mathbf{~ n m}$. Photomedicine and Laser Surgery 26 (5):451-453. doi: doi:10.1089/pho.2007.2218.

39. Oron U., $u \partial p$. 2001. Low-energy laser irradiation reduces formation of scar tissue after myocardial infarction in rats and dogs. Circulation 103 (2):296-301. doi: 10.1161/01.CIR.103.2.296.

40. Rojas J.C., $u \partial p$. 2008. Neuroprotective effects of near-infrared light in an in vivo model of mitochondrial optic neuropathy. The Journal of Neuroscience 28 (50):13511-13521. doi: 10.1523/jneurosci.3457-08.2008. 
41. Lapchak P.A., De Taboada L. 2010. Transcranial near infrared laser treatment (NILT) increases cortical adenosine-5'-triphosphate (ATP) content following embolic strokes in rabbits. Brain Research 1306:100-105. doi: 10.1016/j.brainres.2009.10.022.

42. Ferraresi C., $u \partial p$. 2015. Light-emitting diode therapy in exercise-trained mice increases muscle performance, cytochrome coxidase activity, ATP and cell proliferation. Journal of Biophotonics 8 (9):740-754. doi: 10.1002/jbio.201400087.

43. Бучаченко А.Л. 2014. Магнитно-зависимые молекулярные и химические процессы в биохимии, генетике и медицине. Успехи химии 83 (1):1-12.

44. Buchachenko A., Lawler R.G. 2017. New possibilities for magnetic control of chemical and biochemical reactions. Accounts of Chemical Research 50 (4):877-884. doi: 10.1021/acs.accounts.6b00608.

45. Павлов С.Е. 2008. Лазерная терапия с использованием терапевтических матричных магнито-ИК-лазерных аппаратов. Москва.

46. Картелишев А.В., $u$ др. 2012. Лазерная терапия и профилактика. Москва: Практическая медицина.

47. Герасименко М.Ю., $и$ др. 2015. Лазерная терапия в лечебно-реабилитационных и профилактических программах: Клинические рекомендации. Moscow: Triada.

48. Асирян Е., Новиков П. 2015. Лазерное излучение и его влияние на иммунную систему. Аллергология и Иммунология в Педиатрии (3 (42)).

49. Москвин С.В., Хадарцев А.А. 2019. Методы эффективной лазерной терапии при лечении больных бронхиальной астмой (обзор литературы). Becтник новых медииинских технологий 13 (5).

50. Горяйнов И., $и \partial p$. 1998. Функциональная активность лейкоцитов человека под влиянием инфракрасного лазерного облучения. Иммунология 2:32-34.

51. Гизингер О., $u$ дp. 2011. Роль физиотерапевтических воздействий в коррекции дисфункций факторов противоинфекционной защиты организма (Обзор литературы). Вестник новых медицинских технологий 18 (4).

52. Бурдули Н., Габуева А. 2016. Влияние низкоинтенсивного лазерного облучения крови на функциональную активность нейтрофилов у больных внебольничной пневмонией. Вопросы курортологии, физиотерапии и лечебной физической культуры $93(2): 9-12$.

53. Ковалева Л., $u$ др. 2002. Сравнение различных методов коррекции иммунитета у больных вторичными пневмониями. Бюллетень физиологии и патологии дыхания (12).

54. Шейко Е., $u$ дp. 2010. Иммунокоррекция монохромным светодиодным излучением красного спектра у больных раком легкого. Лазерная медицина 14 (2):49-52.

55. Иллек Я., $u$ дp. 2005. Влияние магнитоинфракрасной лазерной терапии на клинико-функциональные показатели и состояние иммунитета у детей с тяжелым течением бронхиальной астмы. Педиатрия. Журнал им. ГН Сперанского $84(6)$.

56. Батырова M.Е., $и$ дp. 2017. Динамика некоторых показателей цитокинового профиля при экссудативном плеврите различной этиологии под воздействием внутривенного лазерного облучения крови (промежуточные результаты). Лазерная медииина 21 (3):28-31.

57. Сутягина Д., $u$ дp. 2019. Комплексная терапия инфильтративного туберкулеза легких с использованием низкоинтенсивного лазерного излучения: особенности динамики цитокинов, эффективность лечения. Вестник новых медицинских технологий. Электронное издание 13 (1). doi: 10.24411/2075-4094-2019-16229.

58. Ziemssen T., Kern S. 2007. Psychoneuroimmunology-cross-talk between the immune and nervous systems. Journal of neurology 254 (2):II8-II11. doi: 10.1007/s00415-0072003-8. 
59. Gottlieb R.L., Wallace L.B. 2010. Syntonic phototherapy. Photomedicine and Laser Surgery 28 (4):449-452. doi: 10.1089/pho.2010.9933.

60. Москвин С.В., Купеев В.Г. 2007. Лазерная хромо-и цветотерапия. Москва - Тверь: Триада.

61. Mawson R., $u$ др. 2011. Ultrasound in enzyme activation and inactivation. In Ultrasound technologies for food and bioprocessing, 369-404. Springer.

62. Huang G., $u$ p p. 2017. Effects of ultrasound on microbial growth and enzyme activity. Ultrasonics Sonochemistry 37:144-149. doi: 10.1016/j.ultsonch.2016.12.018.

63. Nadar S.S., Rathod V.K. 2017. Ultrasound assisted intensification of enzyme activity and its properties: a mini-review. World Journal of Microbiology and Biotechnology 33 (9):170. doi: 10.1007/s11274-017-2322-6.

64. Storey K.B. 2005. Functional metabolism: regulation and adaptation: John Wiley \& Sons.

65. Wegner A., $u \partial p$. 2015. How metabolites modulate metabolic flux. Current Opinion in Biotechnology 34 (Supplement C):16-22. doi: 10.1016/j.copbio.2014.11.008.

66. Francis C.W., $u \partial p$. 1995. Ultrasound accelerates transport of recombinant tissue plasminogen activator into clots. Ultrasound in Medicine \& Biology 21 (3):419-424. doi: 10.1016/0301-5629(94)00119-X.

67. Sakakibara M., $u \partial p$. 1996. Influence of ultrasound irradiation on hydrolysis of sucrose catalyzed by invertase. Enzyme and Microbial Technology 18 (6):444-448. doi: 10.1016/0141-0229(95)00128-X.

68. Suchkova V., $u \partial p$. 2002. Ultrasound enhancement of fibrinolysis at frequencies of 27 to 100 kHz. Ultrasound in Medicine \& Biology 28 (3):377-382. doi: 10.1016/S03015629(01)00522-1.

69. Suchkova V., $u$ $\partial p$. 1998. Enhancement of fibrinolysis with $\mathbf{4 0 - k H z}$ ultrasound. Circulation 98 (10):1030-1035. doi: 10.1161/01.cir.98.10.1030.

70. Никитин В., $u$ дp. 2018. Лазерно-ультразвуковая терапия в комплексном лечении хронической обструктивной болезни легких. Туберкулез и болезни легких 96 (8):3136.

71. Paolillo A., $u \partial p$. 2015. Synergic effects of ultrasound and laser on the pain relief in women with hand osteoarthritis. Lasers in Medical Science 30 (1):279-286. doi: 10.1007/s10103-014-1659-4.

72. Илларионов В.Е., Симоненко В. 2007. Современные методы физиотерапии: Медицина.

73. Громов А.А., $u$ дp. 2020. Коронавирусная болезнь COVID-19: неиспользованные возможности терапии. Русский медииинский журнал 9. 